\title{
Bioenergetic Abnormalities Associated with Severe Left Ventricular Hypertrophy
}

Jianyi Zhang, Hellmut Merkle, Kristy Hendrich, Michael Garwood, Arthur H. L. From, Kamil Ugurbil, and Robert J. Bache Departments of Medicine, Biochemistry, and Radiology, the Center for Magnetic Resonance Research, University of Minnesota Health Sciences Center; and Department of Veterans Affairs Medical Center, Minneapolis, Minnesota 55455

\section{Abstract}

Transmurally localized ${ }^{31} \mathrm{P}$-nuclear magnetic resonance spectroscopy (NMR) was used to study the effect of severe pressure overload left ventricular hypertrophy (LVH) on myocardial high energy phosphate content. Studies were performed on 8 normal dogs and 12 dogs with severe left ventricular hypertrophy produced by banding the ascending aorta at 8 wk of age. Spatially localized ${ }^{31} \mathrm{P}-\mathrm{NMR}$ spectroscopy provided measurements of the transmural distribution of myocardial ATP, phosphocreatine $(C P)$, and inorganic phosphate $\left(P_{i}\right)$; spectra were calibrated from measurements of ATP content in myocardial biopsies using HPLC. Blood flow was measured with microspheres. In hypertrophied hearts during basal conditions, ATP was decreased by $42 \%, \mathrm{CP}$ by $58 \%$, and the CP/ATP ratio by $32 \%$ in comparison with normal. Increasing myocardial blood flow with adenosine did not correct these abnormalities, indicating that they were not the result of persistent hypoperfusion. Atrial pacing at 200 and 240 beats per min caused no change in high energy phosphate content in normal hearts but resulted in further $C P$ depletion with $P_{i}$ accumulation in the inner left ventricular layers of the hypertrophied hearts. These changes were correlated with redistribution of blood flow away from the subendocardium in LVH hearts. These findings demonstrate that high energy phosphate levels and the CP/ATP ratio are significantly decreased in severe $\mathrm{LVH}$. These abnormalities are proportional to the degree of hypertrophy but are not the result of persistent abnormalities of myocardial perfusion. In contrast, depletion of $\mathrm{CP}$ and accumulation of $P_{i}$ during tachycardia in LVH are closely related to the pacing-induced perfusion abnormalities and likely reflect subendocardial ischemia. (J. Clin. Invest. 1993. 92:993-1003.) Key words: phosphocreatine • ATP • magnetic resonance spectroscopy • aortic stenosis

\section{Introduction}

Myocardial hypertrophy is a compensatory mechanism by which the left ventricle adapts to an increased systolic load. Systolic wall stress decreases in proportion to the increased wall thickness until computed wall stress returns to near normal levels $(1,2)$. Despite the apparent appropriateness of the hypertrophic response to an increased systolic load, epidemiologi-

Address correspondence to Dr. Robert J. Bache, Cardiovascular Division, Department of Medicine, University of Minnesota Medical School, Box 338 UMHC, 420 Delaware Street, S.E., Minneapolis, MN 55455.

Received for publication 10 August 1992 and in revised form 27 April 1993.

The Journal of Clinical Investigation, Inc.

Volume 92, August 1993, 993-1003 cal studies indicate that left ventricular hypertrophy $(\mathrm{LVH})^{1}$ is an independent risk factor for the development of angina pectoris, congestive heart failure, and sudden cardiac death $(3,4)$. Experimental studies have demonstrated that a period of apparently stable compensated hypertrophy may be followed by progressive myocardial dysfunction (5). Although the mechanisms responsible for the development of mechanical dysfunction are not fully understood, persistent or inducible abnormalities of myocardial perfusion could contribute to contractile dysfunction in the hypertrophied myocardium. In support of this, clinical and laboratory studies have demonstrated that the hypertrophied left ventricle has increased vulnerability to ischemia during stress $(6,7)$. Thus, patients with LVH secondary to pressure overload may develop typical exertional angina pectoris without evidence of coronary artery disease (8). In dogs with LVH secondary to ascending aortic banding, treadmill exercise results in subendocardial underperfusion associated with subendocardial contractile dysfunction $(6,9)$. Myocardial ischemia is known to cause both decreased high energy phosphate (HEP) levels and systolic dysfunction (10-12). Thus, sustained or repetitive episodes of hypoperfusion in the severely hypertrophied left ventricle might be associated with abnormalities of energy metabolism.

The present study was carried out to examine myocardial HEP compound content in the normal and severely hypertrophied canine left ventricle. Measurements were obtained both under basal conditions and during rapid pacing to determine whether hypertrophy compromises the ability of the heart to tolerate the stress of tachycardia. To determine whether abnormalities of HEP are the result of inadequate myocardial perfusion, measurements were repeated while myocardial blood flow was increased by pharmacological coronary vasodilation. The ability to obtain spatially localized ${ }^{31} \mathrm{P}$-nuclear magnetic resonance (NMR) spectra across the left ventricular (LV) wall allowed discrete measurements from subepicardial, midmyocardial, and subendocardial regions without cross-contamination (11-14). This is of special importance in the setting of LVH, where perfusion abnormalities occur preferentially in the subendocardium $(6,7,9)$.

\section{Methods}

Studies were performed in 12 dogs in which LVH had been produced by banding the ascending aorta, as well as in 8 normal adult mongrel dogs, which served as a control group. At $8 \mathrm{wk}$ of age the dogs in which hypertrophy was to be produced were anesthetized with sodium pentobarbital $(25-30 \mathrm{mg} / \mathrm{kg}$, i.v.), intubated, and ventilated with a respirator. A right thoracotomy was performed in the third intercostal space

1. Abbreviations used in this paper: $\mathrm{CK}$, creatine kinase; $\mathrm{CP}$, phosphocreatine; HEP, high energy phosphate; LV, left ventricular; LVEDP, LV end-diastolic pressure; LVH, LV hypertrophy; LVSP, LV systolic pressure; NMR, nuclear magnetic resonance; $P_{i}$, inorganic phosphate. 
and the ascending aorta, $\sim 1.5 \mathrm{~cm}$ above the aortic valve, was mobilized. The aorta was encircled with a polyethylene band $2.5 \mathrm{~mm}$ in width. While simultaneously measuring $\mathrm{LV}$ and distal aortic pressures, the band was tightened until a $20-30 \mathrm{mmHg}$ peak systolic pressure gradient was achieved across the constriction. The chest was then closed in layers, the pneumothorax evacuated with a chest tube, and the animal allowed to recover. The dogs were subsequently maintained in enclosed runs on a standard laboratory diet. LVH occurred progressively as the area of aortic constriction remained fixed in the face of normal body growth. None of the animals developed clinical evidence of heart failure and none received treatment for heart failure.

Animals were returned to the laboratory for study at $\sim 1$ yr of age. Animals were premedicated with morphine sulphate $(1 \mathrm{mg} / \mathrm{kg}$, s.c.), anesthetized with alpha-chloralose $(100 \mathrm{mg} / \mathrm{kg}$, i.v., followed by an infusion of $10 \mathrm{mg} / \mathrm{kg}$ per $\mathrm{h}$ ), intubated, and ventilated with a respirator. A left thoracotomy was performed in the fourth intercostal space and the heart was suspended in a pericardial cradle. Heparin-salinefilled polyvinylchloride catheters, $3.0 \mathrm{~mm}$ outer diameter, were introduced into both femoral arteries and advanced into the ascending aorta for pressure measurement and blood sampling. Similar catheters were introduced into the left atrium via the atrial appendage and the left ventricle via the apical dimple. A bipolar pacing electrode was sutured to the right atrial appendage. An NMR surface coil was sutured to the epicardial surface of the left ventricle in the region perfused by the left anterior descending coronary artery. The surface coil was $35 \mathrm{~mm}$ in diameter for animals with aortic banding and $28 \mathrm{~mm}$ in diameter for normal animals. The coil was constructed of a single turn of silver wire and incorporated a single 33-pF capacitor. A polyethylene capillary filled with $3 \mathrm{M}$ phosphonoacetic acid was cemented across the inner diameter of the coil to facilitate calibration. The coil leads were connected to a balance-tuned circuit external and perpendicular to the thoracotomy incision. The animals were then placed in a lucite cradle, which was introduced into the bore of the magnet.

${ }^{31} P-N M R$ spectroscopy. Spatially localized ${ }^{31} \mathrm{P}-\mathrm{NMR}$ spectroscopy was performed using the rotating frame experiment using adiabatic plane-rotation pulses for phase modulation (RAPP) for image-selected in vivo spectroscopy (ISIS) technique (13). The RAPP-ISIS technique is based on a recently developed adiabatic plane-rotation pulse and yields $\sim 40 \%$ gain in the signal/noise ratio relative to our previously used amplitude-modulated Fourier series window longitudinally modulated, using adiabatic excitation (FLAX) ISIS technique (14), while providing similar performance in terms of spatial localization. Detailed experiments documenting voxel profiles, voxel volumes, and spatial resolution with this method in phantoms and in intact hearts have been previously published (see reference 13 for detailed discussion and references). The RAPP-ISIS technique restricts signal origin to a two-dimensional column perpendicular to the $\mathrm{LV}$ wall with further localization to five layers across the column and, hence, across the LV wall. The column size was $18 \times 18 \mathrm{~mm}$ for the normal hearts and $25 \times 25$ $\mathrm{mm}$ for the hypertrophied hearts. Localization along the column was based on $B_{1}$ phase-encoding and used a nine-term Fourier series window approach as previously described (15). Complete transmural data sets were obtained in 10-min time blocks with a pulse repetition time of $6 \mathrm{~s}$, which allowed full relaxation for ATP and inorganic phosphate $\left(P_{i}\right)$ and $>95 \%$ relaxation of the phosphocreatine $(C P)$ resonance. Data acquisition was gated to the cardiac and respiratory cycles by using the LV pressure trace as the master clock to drive both the respirator and the spectrometer as previously described (14). Two consecutive 10min data sets were obtained and subsequently averaged to enhance the signal/noise ratio. A total of 96 scans were accumulated within each 10 -min time period. Differences in integrated peaks between the first and second 10 -min data sets for each intervention did not exceed $\pm 5 \%$.

Measurement of myocardial blood flow. Myocardial blood flow was measured with microspheres $15 \mu \mathrm{m}$ in diameter labeled with ${ }^{125} \mathrm{I},{ }^{141} \mathrm{Ce}$, ${ }^{51} \mathrm{Cr},{ }^{85} \mathrm{Sr},{ }^{95} \mathrm{Nb}$, or ${ }^{46} \mathrm{Sc}$ ( $3 \mathrm{M}$ Co., St. Paul, $\mathrm{MN}$ and New England Nuclear, Boston, MA). Microspheres diluted in $10 \%$ low molecular weight dextran were agitated in an ultrasonic mixer and vortex agitator for $\geq 15 \mathrm{~min}$ before injection. During each intervention, $2 \times 10^{6} \mathrm{micro}-$ spheres were delivered into the left atrium and flushed with normal saline. A reference sample of arterial blood was withdrawn from the ascending aortic catheter at a rate of $15 \mathrm{ml} / \mathrm{min}$ beginning with the microsphere injection and continuing for $120 \mathrm{~s}$. After completion of the experiment, the fixed heart was sectioned into four transverse rings from base to apex so that one myocardial ring, $2 \mathrm{~cm}$ in thickness, included the area of left ventricle located directly under the surface coil. Each ring was divided into six radial sections and then subdivided into three transmural layers of equal thickness. The resultant specimens were weighed on an analytical balance and placed into vials for counting. Radioactivity of myocardial and blood reference specimens was determined using a gamma spectrometer (model 5912; Packard Instrument Co., Inc., Downers Grove, IL) at window settings appropriate for the combination of radioisotopes used during the study. The cpm recorded in each energy window were corrected for background activity and overlapping counts contributed by the associated isotopes with a digital computer. Myocardial blood flow was computed using the formula $Q_{\mathrm{m}}=Q_{\mathrm{r}} \times C_{\mathrm{m}} / Q_{\mathrm{r}}$, where $Q_{\mathrm{m}}=$ myocardial blood flow $(\mathrm{ml} /$ $\min ), Q_{\mathrm{r}}=$ reference blood flow rate $(\mathrm{ml} / \mathrm{min}), C_{\mathrm{m}}=$ counts per minute of the myocardial specimen, and $C_{\mathrm{r}}=$ counts per minute of the reference blood flow specimen. Blood flows $(\mathrm{ml} / \mathrm{min})$ were divided by the sample weight and expressed as $\mathrm{ml} / \mathrm{min}$ per $\mathrm{g}$ of myocardium.

Tissue preparation. At the end of the study, myocardial biopsies ( $\sim 10 \mathrm{mg}$ each ) were obtained from the area beneath the surface coil, using a biopsy forceps precooled to $-70^{\circ} \mathrm{C}$, for later determination of ATP content. After the heart was excised, a transmural tissue sample (3-5 g) was also obtained, divided into three transmural layers from epicardium to endocardium, and frozen for later total creatine content measurement. All the tissue samples were analyzed using an HPLC technique (16). The remainder of the ventricle was fixed in $10 \%$ Formalin for subsequent determination of myocardial blood flow as described above.

Experimental protocol. Aortic and LV pressures were monitored continuously using pressure transducers (Spectramed Inc., Oxnard, CA) positioned at midchest level. LV pressure was recorded at normal and high gain for measurement of end-diastolic pressure. Arterial blood gases and $\mathrm{pH}$ were monitored, and the ventilator rate, volume, and inspired $\mathrm{O}_{2}$ content was adjusted to maintain values within the physiological range. Hemodynamic measurements and ${ }^{31} \mathrm{P}-\mathrm{NMR}$ spectra were first obtained during baseline conditions. Spectroscopic data were acquired over $20-\mathrm{min}$, in two consecutive 10 -min data sets. Midway through the 20 -min acquisition period, between the two 10 min data sets, a microsphere injection was administered for determination of blood flow.

After completion of the control measurements, coronary vasodilation was produced by administration of adenosine $(1 \mathrm{mg} / \mathrm{kg}$ per min, i.v.). $5 \mathrm{~min}$ after beginning the adenosine infusion, ${ }^{31} \mathrm{P}-\mathrm{NMR}$ spectra acquisition was again begun. A second injection of microspheres was administered midway through the 20 -min data acquisition period. After completion of the NMR data acquisition, the adenosine infusion was discontinued and a period of $20 \mathrm{~min}$ was allowed for hemodynamic variables to return to control conditions. To evaluate the effect of tachycardia, atrial pacing was then carried out using a physiological stimulator (model S-88, Grass Instrument Co., Quincy, MA) delivering rectangular pulses $3 \mathrm{~ms}$ in duration at $25 \%$ above threshold voltage. Pacing was first performed at a heart rate of 200 beats per min. Hemodynamic data were monitored continuously and NMR spectra were obtained beginning 2 min after the onset of pacing and continuing for a total of $20 \mathrm{~min}$. Pacing was then discontinued for 20-30 min to allow hemodynamic variables and nontransmural spectra to return to baseline conditions. Pacing was then begun at 240 beats per min. Spectra were again obtained in two 10-min data sets and microspheres were administered between the first and second periods of NMR sampling for determination of blood flow.

Data analysis. Peaks corresponding to the resonant frequencies of CP, ATP, and $P_{i}$ were integrated from the ${ }^{31} \mathrm{P}-\mathrm{NMR}$ spectra and expressed as normalized values compared with the initial control value for that voxel and as CP/ATP and $P_{i} / A T P$ ratios for each voxel during 
Table I. Anatomic data from 8 normal dogs and 12 dogs with $L V H$

\begin{tabular}{lccc}
\hline & LV weight & Body weight & LV \\
\hline & $g$ & $k g$ & $g / k g$ \\
Normal & $84.3 \pm 5.2$ & $19.6 \pm 0.7$ & $4.3 \pm 0.14$ \\
LVH & $165.1 \pm 11.4^{*}$ & $19.6 \pm 1.3$ & $8.9 \pm 0.67^{*}$ \\
\hline
\end{tabular}

Values are mean \pm SEM. ${ }^{*} P<0.01$ in comparison with Normal.

each intervention. Phosphorus spectra from the first, third, and fifth voxels were taken to represent the subepicardium, midwall, and subendocardium, respectively. A voxel-shifting technique (15) was applied when necessary to ensure that the reference peak had the same integrated value for each intervention. In all normal control animals and in four dogs with hypertrophy, the ATP value obtained from the epicardial biopsy was used to calibrate the subepicardial ATP resonance obtained from a spectrum recorded immediately before the biopsy was taken. As described earlier, total tissue creatine $\left(\left[\mathrm{Cr}_{\text {total }}\right]\right)$ was determined from the transmural tissue sample and used in the calculation of ADP. Myocardial ADP content was calculated using the creatine kinase equilibrium equation (17): $[\mathrm{ADP}]=\left([\mathrm{ATP}] \times\left[\mathrm{Cr}_{\text {free }}\right]\right) /([\mathrm{CP}]$ $\left.\times \mathrm{K}_{\text {eq }} \times\left[\mathrm{H}^{+}\right]\right)$, where $\left[\mathrm{Cr}_{\text {free }}\right]=\left[\mathrm{Cr}_{\text {total }}\right]-[\mathrm{CP}]$. Since ATP values obtained from biopsy specimens in animals with hypertrophy fell within a narrow range, ADP values for animals in which biopsies were not obtained were calculated using the mean ATP value for the group.

Hemodynamic and metabolic data and regional myocardial blood flow measurements were analyzed using one-way analysis of variance with replications. A value of $P<0.05$ was required for statistical significance. When a significant result was found, individual comparisons were performed using the Scheffé method.

\section{Results}

Anatomic data. As shown in Table I, LV weights ranged from 62.1 to $102.5 \mathrm{~g}$ in the normal animals and were significantly increased at 91.1 to $250.0 \mathrm{~g}$ in the animals with aortic banding
$(P<0.01)$. The LV weight/body weight ratio in animals with aortic banding was $8.9 \pm 0.7 \mathrm{~g} / \mathrm{kg}$ (range $5.0-12.2 \mathrm{~g} / \mathrm{kg}$ ) versus $4.3 \pm 0.14 \mathrm{~g} / \mathrm{kg}$ ( range $3.5-4.9 \mathrm{~g} / \mathrm{kg}$ ) in the normal group $(P$ $<0.01$ ), indicating a $107 \%$ mean increase of relative LV mass in the animals with aortic banding.

Hemodynamic data. The hemodynamic measurements are summarized in Table II. Heart rates were not significantly different between the two groups during any experimental condition. Mean aortic pressure during control conditions was not significantly different between the two groups. During adenosine infusion, mean aortic pressure tended to decrease in both groups, but this was significant only in the normal group. Pacing tended to decrease aortic pressure in dogs with aortic banding, but this difference did not achieve statistical significance. LV systolic pressure (LVSP) was significantly increased in the LVH hearts during all interventions. Adenosine infusion caused a decrease in LVSP in both groups, but this was significant only in the normal animals. LVSP did not change in the normal animals during pacing but decreased significantly in animals with hypertrophy $(P<0.05)$. LV end-diastolic pressure (LVEDP) was significantly increased in dogs with aortic banding. Linear-regression analysis demonstrated a modest direct relationship between the $\mathrm{LV}$ weight / body weight ratio and LVEDP $(y=1.73 x-3.8 ; r=0.50)$. Pacing produced progressive increases of end-diastolic pressure in LVH hearts but not normal hearts.

Myocardial blood flow. Myocardial blood flows measured with microspheres are shown in Tables III and IV, and Fig. 1. During basal conditions, hypertrophied hearts tended to have higher blood flow per gram of myocardial tissue. There was a transmural perfusion gradient in the normal hearts during baseline conditions with highest flows in the subendocardium. This gradient was reversed in the hypertrophied hearts, as demonstrated by a significantly decreased subendocardial/subepicardial flow ratio $(P<0.05$, Table III $)$. Adenosine significantly increased blood flow to all transmural layers in both groups of animals $(P<0.05$, Table III). In the normal hearts, pacing caused an increase of blood flow, which was uniform across the

Table II. Hemodynamic data

\begin{tabular}{|c|c|c|c|c|c|}
\hline & $\begin{array}{l}\text { Heart } \\
\text { rate }\end{array}$ & $\begin{array}{l}\text { Mean aortic } \\
\text { pressure }\end{array}$ & LVSP & LVEDP & $\begin{array}{l}\text { Rate pressure } \\
\text { product }\end{array}$ \\
\hline & (beats per min) & $(m m H g)$ & $(m m H g)$ & $(m m H g)$ & $t(\mathrm{mmHg} /$ beats per min $) \times 10^{-3}$ \\
\hline \multicolumn{6}{|l|}{ Control } \\
\hline $\operatorname{Normal}(n=8)$ & $136 \pm 7$ & $99 \pm 6$ & $120 \pm 5$ & $7 \pm 1$ & $16.4 \pm 1.2$ \\
\hline $\operatorname{LVH}(n=12)$ & $130 \pm 9$ & $93 \pm 6$ & $183 \pm 8^{*}$ & $12 \pm 3^{*}$ & $23.2 \pm 1.4^{*}$ \\
\hline \multicolumn{6}{|l|}{ Adenosine } \\
\hline Normal $(n=8)$ & $146 \pm 5$ & $80 \pm 5^{\ddagger}$ & $101 \pm 5^{\dagger}$ & $8 \pm 1$ & $14.8 \pm 1.1$ \\
\hline $\operatorname{LVH}(n=6)$ & $122 \pm 14$ & $87 \pm 9$ & $176 \pm 8^{*}$ & $11 \pm 2 *$ & $21.1 \pm 2.0^{*}$ \\
\hline \multicolumn{6}{|l|}{ Recontrol } \\
\hline Normal $(n=8)$ & $144 \pm 8$ & $99 \pm 4$ & $117 \pm 4$ & $8 \pm 1$ & $16.9 \pm 1.1$ \\
\hline $\operatorname{LVH}(n=12)$ & $130 \pm 9$ & $97 \pm 5$ & $183 \pm 9^{*}$ & $13 \pm 3^{*}$ & $23.4 \pm 1.5^{*}$ \\
\hline \multicolumn{6}{|c|}{ Pacing 200 beats per min } \\
\hline Normal $(n=8)$ & $200^{\dagger}$ & $99 \pm 5$ & $116 \pm 5$ & $7 \pm 1$ & $23.1 \pm 10^{\dagger}$ \\
\hline $\operatorname{LVH}(n=9)$ & $200^{\dagger}$ & $89 \pm 6$ & $161 \pm 10^{*}$ & $15 \pm 3^{*}$ & $32.9 \pm 2.0^{*}$ \\
\hline \multicolumn{6}{|c|}{ Pacing 240 beats per min } \\
\hline Normal $(n=8)$ & $241 \pm 1^{\dagger}$ & $96 \pm 4$ & $114 \pm 5$ & $8 \pm 1$ & $27.3 \pm 1.2^{\dagger}$ \\
\hline $\operatorname{LVH}(n=10)$ & $241 \pm 1^{\dagger}$ & $91 \pm 5$ & $153 \pm 10^{* \dagger}$ & $17 \pm 3^{*}$ & $36.9 \pm 2.3^{* \dagger}$ \\
\hline
\end{tabular}

Values are mean \pm SEM. ${ }^{*} P<0.05$ in comparison with Normal. ${ }^{\star} P<0.05$ in comparison with the respective Control measurement. 
Table III. Myocardial Blood Flow to Three Transmural Layers of the Left Ventricle During Control Conditions and in Response to Adenosine (1.0 $\mathrm{mg} / \mathrm{kg}$ per minn iv)

\begin{tabular}{|c|c|c|c|c|c|}
\hline & \multicolumn{5}{|c|}{ Myocardial blood flow } \\
\hline & EPI & MID & ENDO & Mean & ENDO/EPI \\
\hline & \multicolumn{5}{|c|}{$\mathrm{ml} / \mathrm{min}$ per $\mathrm{g}$} \\
\hline \multicolumn{6}{|l|}{ Control } \\
\hline Normal $(n=8)$ & $0.84 \pm 0.10$ & $0.83 \pm 0.08$ & $0.91 \pm 0.08$ & $0.86 \pm 0.08$ & $1.15 \pm 0.12$ \\
\hline $\operatorname{LVH}(n=6)$ & $1.33 \pm 0.16$ & $1.10 \pm 0.18$ & $1.19 \pm 0.15$ & $1.20 \pm 0.16$ & $0.89 \pm 0.07^{\ddagger}$ \\
\hline \multicolumn{6}{|l|}{ Adenosine } \\
\hline Normal $(n=8)$ & $4.17 \pm 0.53^{*}$ & $3.88 \pm 0.27^{*}$ & $4.04 \pm 0.40^{*}$ & $4.03 \pm 0.38^{*}$ & $0.98 \pm 0.05$ \\
\hline $\operatorname{LVH}(n=6)$ & $4.01 \pm 0.33^{*}$ & $3.81 \pm 0.33^{*}$ & $3.98 \pm 0.30^{*}$ & $3.94 \pm 0.17^{*}$ & $1.05 \pm 0.19$ \\
\hline
\end{tabular}

Values are mean \pm SEM. ENDO, subendocardium; EPI, subepicardium; MID, midwall of the left ventricule; LVH, left ventricular hypertrophy. ${ }^{*} P<0.05$ in comparison with the respective Control measurement. ${ }^{\ddagger} P<0.05$ in comparison with Normal.

LV wall (Fig. 1 and Table IV). Pacing also caused an increase of mean blood flow in the hypertrophied hearts, but this was associated with redistribution of perfusion away from the subendocardium ( Table IV).

HEP distribution during basal conditions and hyperemia. Typical transmural spectra during control conditions are shown in Fig. 2. Fig. $2 A$ shows a set of spectra from a normal heart, Fig. $2 B$ from a heart with compensated LVH, and Fig. 2 $C$ from a $\mathrm{LVH}$ heart with failure as evidenced by an increase of LVEDP to $25 \mathrm{mmHg}$ and a dilated LV cavity. Spectra are scaled to optimize visualization of the resonance peaks; thus, only the CP/ATP ratios can be compared between spectra. The transmural spectra are displayed so that voxel 1 (subepicardium) represents the outermost layer of the LV wall and includes signal from the capillary of the surface coil, whereas voxel 5 represents the innermost layer of the LV wall and contains the 2,3-diphosphoglycerate resonances arising from erythrocytes within the $L V$ chamber. As seen in Fig. 2, and Tables $V$ and VI, in each myocardial layer the CP/ATP ratio was significantly lower in hypertrophied than in normal hearts under control conditions $(P<0.01)$. Within the signal/noise ratio characteristics of the spectra, $P_{i}$ was not detectable in either group of animals during the basal state. Adenosine infusion tended to cause an increase of the CP/ATP ratio in the innermost layers in both groups, but this did not reach statistical significance. Adenosine infusion did not change the HEP distribution in the outer layers of either group. The $P_{i}$ level was too low to be detected in either group during adenosine infusion. Three of the six animals with LVH in which adenosine infusion was performed had LVEDP of $\geq 15 \mathrm{mmHg}$; there was no difference in response of HEP between animals with end-diastolic pressure above or below $15 \mathrm{mmHg}$.

HEP levels during pacing-induced tachycardia. Typical transmural spectra during sinus rhythm and during pacing in a normal heart are shown in Fig. 3 and from a hypertrophied heart in Fig. 4. Pacing did not cause a significant change of HEP distribution in the normal hearts (Table VI). In the hypertrophied hearts during pacing at 240 beats per min, the subendocardial layer CP / ATP ratio decreased significantly in comparison with the same voxel during sinus rhythm (Fig. 4 and Table VI). During pacing, $P_{i}$ increased significantly in the midwall and subendocardial layers in the LVH hearts $(P<0.05)$

Table IV. Mycoardical Blood Flow to Three Transmural LV Layers from Epicardium to Endocardium in 8 Normal Animals and 12 Animals with LVH During Control Conditions and in Response to Pacing at 200 and 240 beats per min

\begin{tabular}{|c|c|c|c|c|c|}
\hline & \multicolumn{5}{|c|}{ Myocardial blood flow } \\
\hline & EPI & MID & ENDO & Mean & ENDO/EPI \\
\hline & \multicolumn{5}{|c|}{ ml/min per $g$} \\
\hline \multicolumn{6}{|l|}{ Control } \\
\hline Normal $(n=8)$ & $0.84 \pm 0.10$ & $0.83 \pm 0.08$ & $0.91 \pm 0.08$ & $0.86 \pm 0.08$ & $1.15 \pm 0.12$ \\
\hline $\operatorname{LVH}(n=12)$ & $1.34 \pm 0.12^{\ddagger}$ & $1.22 \pm 0.15$ & $1.26 \pm 0.12^{\ddagger}$ & $1.27 \pm 0.13^{\ddagger}$ & $0.96 \pm 0.06^{\ddagger}$ \\
\hline \multicolumn{6}{|c|}{ Pacing 200 beats per min } \\
\hline Normal $(n=8)$ & $1.10 \pm 0.15^{*}$ & $1.10 \pm 0.12^{*}$ & $1.14 \pm 0.07^{*}$ & $1.11 \pm 0.11^{*}$ & $1.12 \pm 0.10$ \\
\hline LVH $(n=6)$ & $1.71 \pm 0.25$ & $1.43 \pm 0.20$ & $1.37 \pm 0.24$ & $1.50 \pm 0.21$ & $0.84 \pm 0.12$ \\
\hline \multicolumn{6}{|c|}{ Pacing 240 beats per min } \\
\hline Normal $(n=8)$ & $1.17 \pm 0.16^{*}$ & $1.17 \pm 0.13^{*}$ & $1.19 \pm 0.09^{*}$ & $1.17 \pm 0.12^{*}$ & $1.10 \pm 0.11$ \\
\hline LVH $(n=8)$ & $1.82 \pm 0.13^{* \ddagger}$ & $1.55 \pm 0.14$ & $1.27 \pm 0.11$ & $1.55 \pm 0.11^{\ddagger}$ & $0.72 \pm 0.07^{* \neq}$ \\
\hline
\end{tabular}

Values are mean \pm SEM. EPI, subepicardium; ENDO, subendocardium; MID, midwall; LVH, left ventricular hypertrophy. ${ }^{*} P<0.05$ in comparison with the respective Control measurement. ${ }^{\ddagger} P<0.05$ in comparison with Normal. 

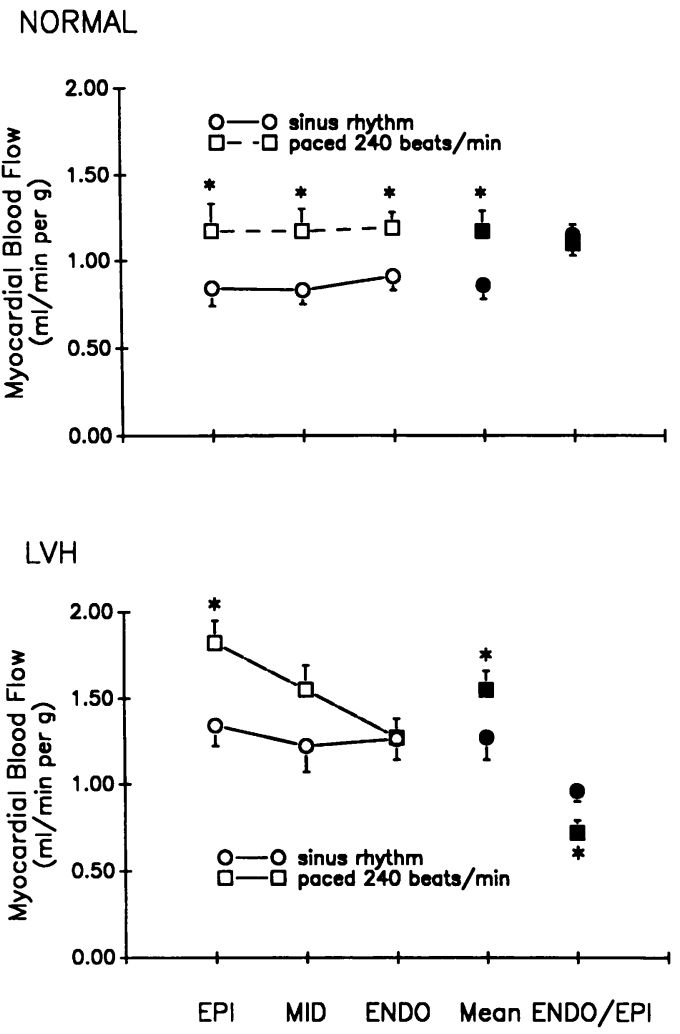

Figure 1. Blood flow to three transmural layers and the ratio of subendocardial/subepicardial flow ( $E N D O / E P I$ ) during sinus rhythm and during pacing at 240 beats per min in eight normal dogs and eight dogs with LVH. ${ }^{*} P<0.05$ in comparison with sinus rhythm.

(Fig. 4 and Table VII). Among the 10 dogs with LVH that completed the pacing protocol, $\mathrm{P}_{\mathrm{i}}$ was detected as follows: during sinus rhythm, no heart had detectable $P_{i}$; during pacing at 200 beats per min, 3 of 10 became positive in the subepicardium, in the midwall four became positive, and in the subendocardium five became positive; and during pacing at 240 beats per min, 5 of 10 became positive in the subepicardium, in the midwall nine became positive, and in the subendocardium all became positive. Neither the decrease in CP/ATP ratio nor the increase in $\mathrm{P}_{\mathrm{i}}$ during pacing were related to the presence of an elevated LVEDP during control conditions. ATP values did not change significantly during any experimental condition in either group of animals.

Tissue total creatine and ATP values from biopsy. Subepicardial biopsy ATP values from eight normal hearts and four hearts with LVH are shown in Table VIII. The ATP content was significantly lower in LVH hearts than in normals $(P$ $<0.05)$. Myocardial creatine concentrations are shown in Table IX. Total creatine levels in the hypertrophied hearts were significantly lower than normal in all three layers across the LV wall (Table IX) $(P<0.05)$.

Calculated steady state myocardial ADP concentrations. Calculated ADP concentrations, using ATP values determined from the biopsies, are summarized in Table X. The LVH hearts had significantly higher ADP levels than normal. When the myocardial ADP content for the LVH hearts was plotted against the severity of hypertrophy using the index of LV weight/body weight $(\mathrm{g} / \mathrm{kg})$, a direct correlation was seen (Fig. 5).

\section{Discussion}

The major findings in the current study were $(a)$ under basal conditions, ATP, total creatine levels, and the CP/ATP ratio were significantly lower in hearts with severe $\mathrm{LVH}$ than in normal hearts; $(b)$ increasing myocardial blood flow and oxygen delivery by coronary vasodilation with adenosine did not significantly improve the CP/ATP ratios in LVH hearts; and (c) rapid pacing decreased subendocardial $C P$ / ATP ratios and increased $P_{i} / A T P$ ratios in the midmyocardium and subendocardium of LVH but not normal hearts, and this was associated with hypoperfusion of the midmyocardium and subendocardium in LVH but not normal hearts.

Myocardial perfusion under basal conditions and during hyperemia. Mean myocardial blood flow tended to be increased in the hypertrophied hearts, but the fraction of flow delivered to the subendocardium was significantly decreased. These findings are similar to those previously reported (18, 19). In response to adenosine infusion, mean myocardial blood flow increased $369 \%$ in normal hearts and $228 \%$ in hypertrophied hearts, indicating that the coronary vasodilator reserve was compromised in the hypertrophy group. This difference was largely accounted for by an increased basal flow rate in the hypertrophied hearts. Reduced vasodilator reserve has been previously observed in hypertrophied myocardium (20). However, administration of adenosine increased blood flow considerably above nutrient requirements in both study groups.

HEP levels and transmural distributions under basal conditions and in response to hyperemia. In previous studies of $\mathrm{LVH}$ using several different experimental models and species, both normal $(21,22)$ and decreased (23) CP/ATP ratios have been reported. In the current study of severely hypertrophied hearts, ATP was decreased by $42 \%$, CP by $58 \%$, total creatine by $24 \%$, and the CP/ATP ratio was decreased by $32 \%$. These data were consistent with earlier observations of Fox and Reed (24). In the hypertrophy group, the decreased CP and ATP levels and the lower CP/ATP ratios observed under basal conditions were not a consequence of persistently inadequate perfusion, because when coronary blood flow was increased by adenosine infusion, neither CP levels nor the CP/ATP ratio changed significantly. These data are consistent with those of Scholz et al. (25) showing that oxygen supply/consumption balance is preserved in severely hypertrophied canine myocardium.

Although insufficient ATP precursor content could have prevented a flow-induced increase of ATP, this was not the case with respect to $C P$, since significant quantities of free creatine were available. The enzyme which generates $\mathrm{CP}$, creatine kinase ( $\mathrm{CK}$ ), has been shown to be in equilibrium in intact myocardium (26) and, thus, responds passively to the concentrations of its reactants. In normoxic myocardium the rate-limiting reactant appears to be $\operatorname{ADP}(26,27)$, since ATP levels are high (in relation to the ATP $K_{\mathrm{m}}$ value with respect to CK) and usually stable under a variety of physiological states $(17,27$, 28) (as was the case in the present investigation). Free creatine is also generally nonlimiting. Although a primary alteration of the properties of CK cannot be excluded, the failure of CP to rise when perfusion was increased likely resulted from the persistence of high levels of ADP, which continued to depress the equilibrium values of $\mathrm{CP}(17,27)$.

In the present study, the cause of the higher levels of ADP in the hypertrophied myocardium is conjectural. Possible expla- 


\section{A Normal}

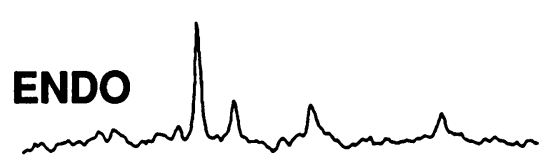

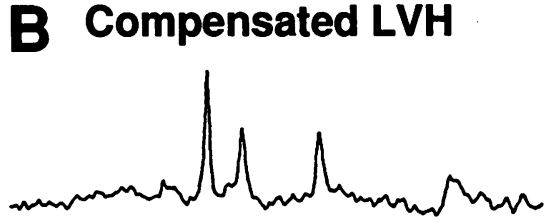

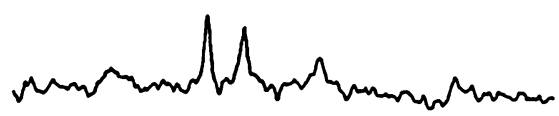

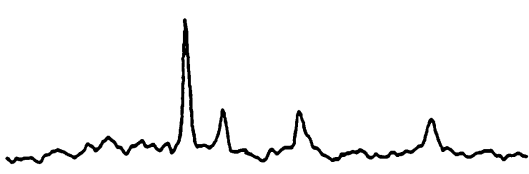

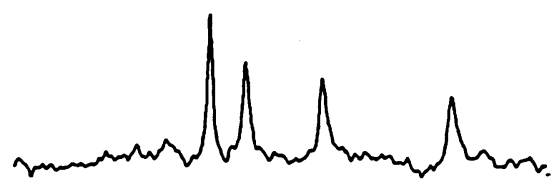

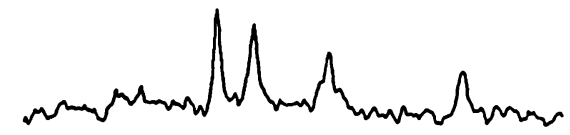

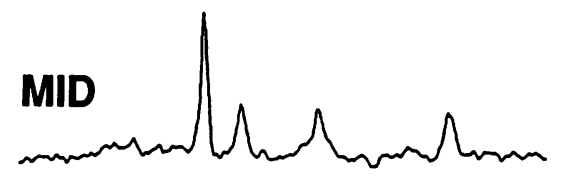

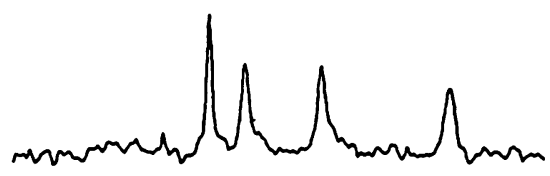

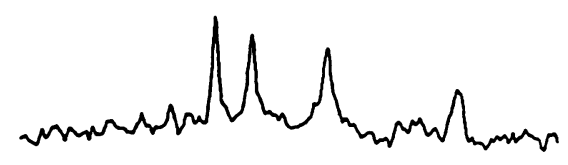

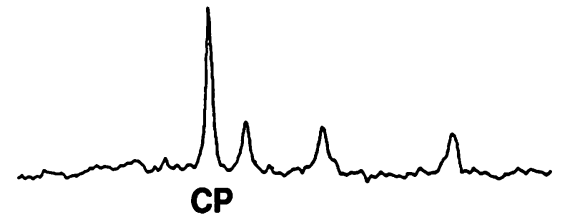

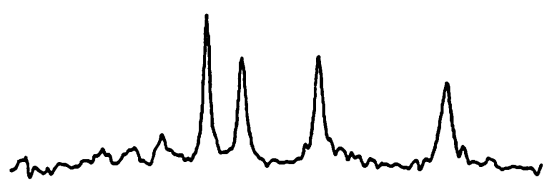

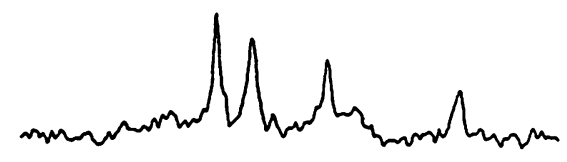
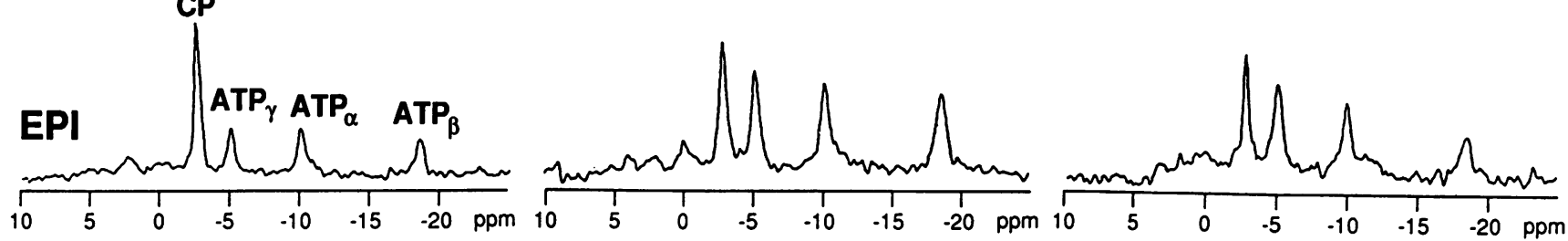

Figure 2. Transmural distribution of HEP concentrations measured with ${ }^{31} \mathrm{P}-\mathrm{NMR}$ during baseline conditions from a normal heart $(A)$, a heart with compensated $\mathrm{LVH}(B)$, and a heart with $\mathrm{LVH}$ and failure evidenced by increased $\mathrm{LV}$ filling pressure to $25 \mathrm{mmHg}(C)$. Each transmural data set consists of a stack of five spectra corresponding to voxels centered around phase angles $45^{\circ}, 60^{\circ}, 90^{\circ}, 120^{\circ}$, and $135^{\circ}$. The $135^{\circ}$ voxels (corresponding to the subepicardium) and the $45^{\circ}$ voxel (corresponding to subendocardium) are the outermost and innermost voxels relative to the surface coil. $E N D O$, subendocardial voxel; $M I D$, midwall voxel; $E P I$, subepicardial voxel. Spectra were scaled to optimize visualization of the resonance peaks, so that only the CP/ATP ratios can be compared between spectra.

nations include decreased oxygen availability to the mitochondria; an increased $\mathrm{O}_{2} K_{\mathrm{m}}$ value with regard to cytochrome $\mathrm{a}, \mathrm{a}_{3}$; reduced $\mathrm{P}_{\mathrm{i}}$ availability to the mitochondrial $\mathrm{H}^{+}$-ATPase; reduced NADH generation resulting from either inadequate exogenous carbon substrate delivery to the cell or disordered intermediary metabolism within the cytosol and/or mitochondria; altered function of the electron transport chain so that a lower mitochondrial proton gradient is maintained; or, lastly,

Table V. Myocardical CP/ATP Ratios in Three Transmural Layers of the Left Ventricle During Control Conditions and in Response to Adenosine (1 $\mathrm{mg} / \mathrm{kg}$ per min, i.v.) in Eight Normal Animals and Six Animals with LVH

\begin{tabular}{llll}
\hline & Subepicardium & Midwall & Subendocardium \\
\hline Control & & & \\
$\quad$ Normal & $2.37 \pm 0.14$ & $2.12 \pm 0.04$ & $2.04 \pm 0.11$ \\
LVH & $1.62 \pm 0.15^{*}$ & $1.61 \pm 0.11^{*}$ & $1.43 \pm 0.06^{*}$ \\
Adenosine & & & \\
$\quad$ Normal & $2.39 \pm 0.12$ & $2.31 \pm 0.12$ & $2.22 \pm 0.07$ \\
LVH & $1.60 \pm 0.13^{*}$ & $1.62 \pm 0.11^{*}$ & $1.50 \pm 0.08^{*}$ \\
\hline
\end{tabular}

Values are mean \pm SEM. ${ }^{*} P<0.05$ in comparison with Normal. altered properties of the mitochondrial $\mathrm{H}^{+}$-ATPase such that the $V_{\max }$ or $K_{\mathrm{m}}$ values with respect to ADP and/or $\mathrm{P}_{\mathrm{i}}$ are increased. All of these possible abnormalities have in common the ability to result in higher ADP levels.

Table VI. Myocardial CP/ATP ratios in Three Transmural Layers of the Left Ventricle During Control Conditions and in Response to Pacing in 8 Normal Animals and 10 Animals with $\mathrm{LVH}$

\begin{tabular}{llll}
\hline & Subepicardium & \multicolumn{1}{c}{ Midwall } & Subendocardium \\
\hline Control & & & \\
$\quad$ Normal & $2.37 \pm 0.14$ & $2.12 \pm 0.04$ & $2.04 \pm 0.11$ \\
$\quad$ LVH & $1.60 \pm 0.09^{\ddagger}$ & $1.51 \pm 0.11^{\dagger}$ & $1.43 \pm 0.12^{\ddagger}$ \\
Pacing 200 beats per min & & & \\
$\quad$ Normal & $2.37 \pm 0.15$ & $2.07 \pm 0.06$ & $2.02 \pm 0.12$ \\
$\quad$ LVH & $1.56 \pm 0.10^{\ddagger}$ & $1.52 \pm 0.12^{\ddagger}$ & $1.42 \pm 0.13^{\ddagger}$ \\
Pacing 240 beats per min & & & \\
$\quad$ Normal & $2.21 \pm 0.05$ & $2.12 \pm 0.07$ & $2.06 \pm 0.08$ \\
$\quad$ LVH & $1.56 \pm 0.10^{\ddagger}$ & $1.39 \pm 0.12^{* \ddagger}$ & $1.15 \pm 0.09^{* \ddagger}$ \\
\hline
\end{tabular}

Values are mean \pm SEM. ${ }^{*} P<0.05$ in comparison with the respective Control measurement. $\quad{ }^{\ddagger} P<0.05$ in comparison with Normal. 


\section{A. Sinus Rhythum}

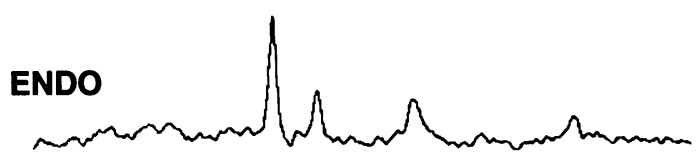

B. Paced: 240 beats/min.

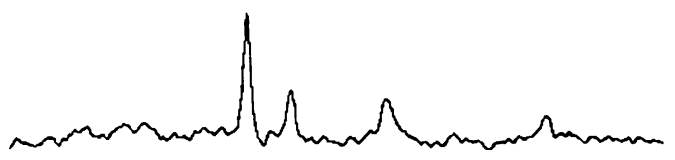

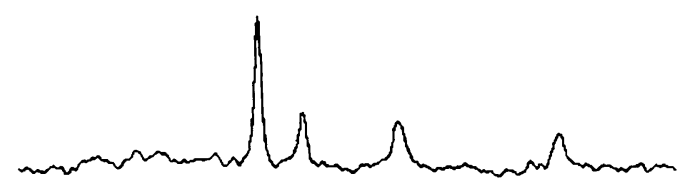
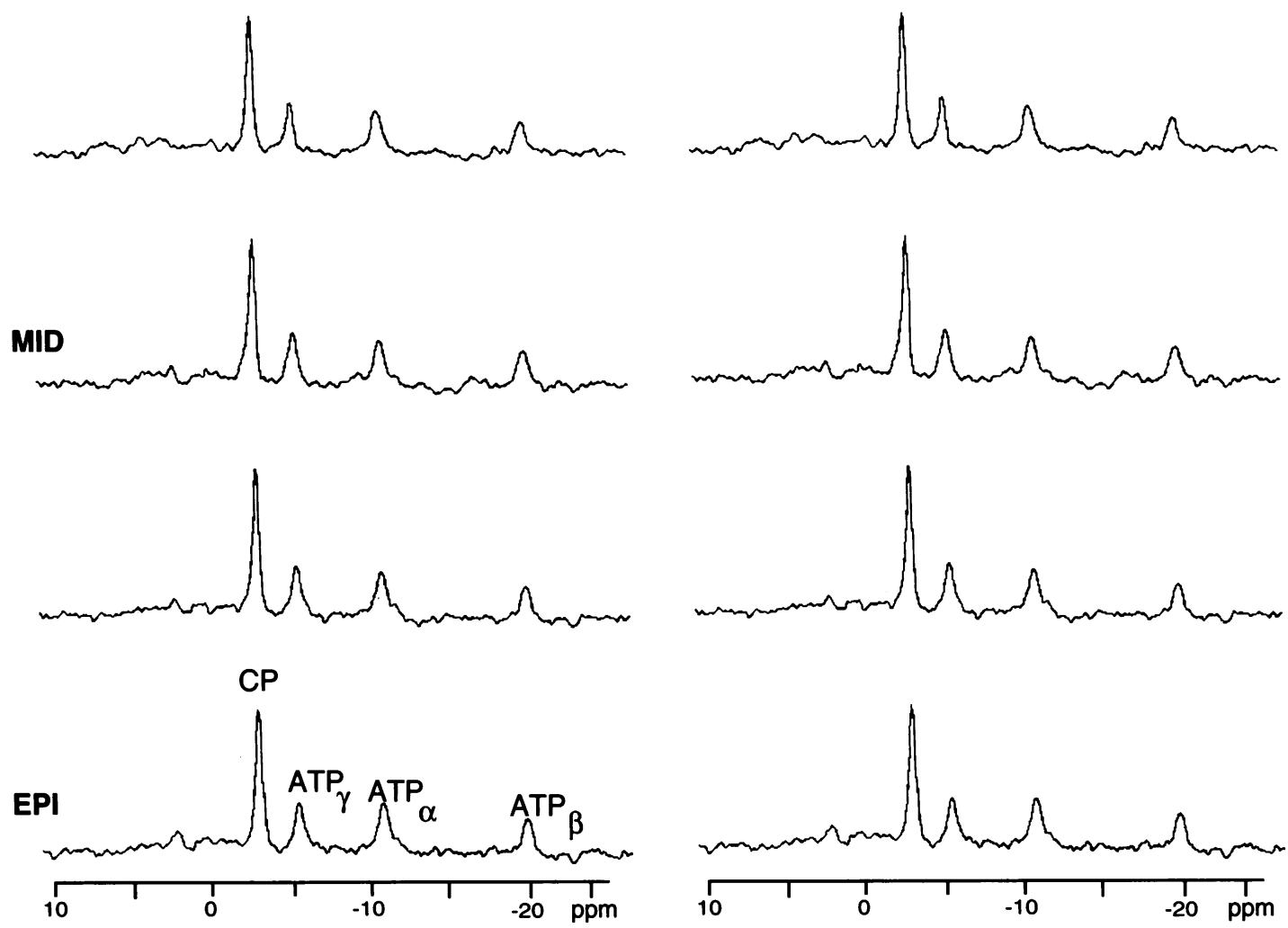

Figure 3. Transmural response of phosphorylated metabolites detected by ${ }^{31} \mathrm{P}-\mathrm{NMR}$ during sinus rhythm and during pacing at 240 beats per min in a normal heart.

Because there is evidence that in intact myocardium ATP synthesis by the $\mathrm{H}^{+}$-ATPase is kinetically regulated by its primary substrates $(17,29)$, alterations in any of the aforementioned variables can potentially affect ADP levels. For example, reduction of intramitochondrial $\mathrm{NADH}$ or $\mathrm{P}_{\mathrm{i}}$ availability or the magnitude of the mitochondrial proton gradient would require that ADP levels rise to support the required rate of ATP synthesis, so long as the other substrate levels were in a range where kinetic regulation remained possible $(17,29)$. The current data exclude the possibility that oxygen delivery to the capillary bed is limiting, since adenosine markedly increased the perfusion in all transmural myocardial layers. However, the data do not exclude the possibility of diffusion limitation of $\mathrm{O}_{2}$ to the mitochondria, resulting from increased intercapillary diffusion distances, which characterize the hypertrophied myocardium (30). Likewise, limitation of carbon substrate delivery to the myocyte seems excluded, but the current observations are inadequate to evaluate the other possibilities listed, and elucidation of the cause of ADP elevation in severely hypertrophied myocardium awaits further investigation. In any event, the reduced levels of $\mathrm{CP}$ appear, at least in part, to be secondary to quantitative or qualitative changes in the means by which the ATP synthetic process is regulated. This alteration is associated with higher levels of ADP at any given rate of energy expenditure.

The cause of the lower ATP and creatine levels in the hypertrophied myocardium is also unclear. ATP synthetic capacity appears to be adequate, as evidenced by the lack of reduction in either ATP or CP values in the outer myocardial layer during rapid pacing. Pacing was associated with increased mechanical activity and presumably a higher rate of ATP expenditure. The loss of adenine nucleotide precursors from repetitive activity-related ischemic episodes is possible. However, perfusion of the subepicardium was well preserved during pacing, and yet subepicardial ATP levels were not higher than those in the deeper myocardial layers. Lastly, creatine is not synthesized by striated muscle but rather is transported into the cell from the perfusing blood against a concentration gradient (31). Thus, abnormalities of creatine levels likely relate to disordered myocyte uptake mechanisms or loss of creatine because of less effective "trapping" of that molecule in the form of CP. These considerations suggest that the causes of the abnormalities in HEP levels in severely hypertrophied myocardium are complex and likely reflect alterations of many cellular characteris- 


\section{A. Sinus Rhythum}

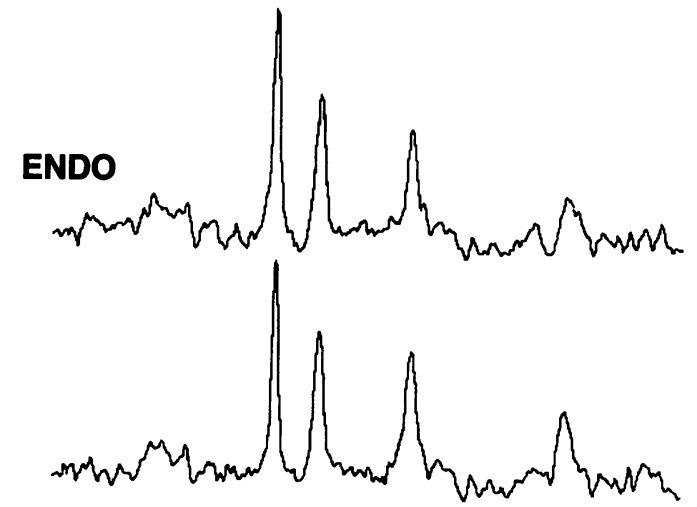

B. Paced: 240 beats/min.

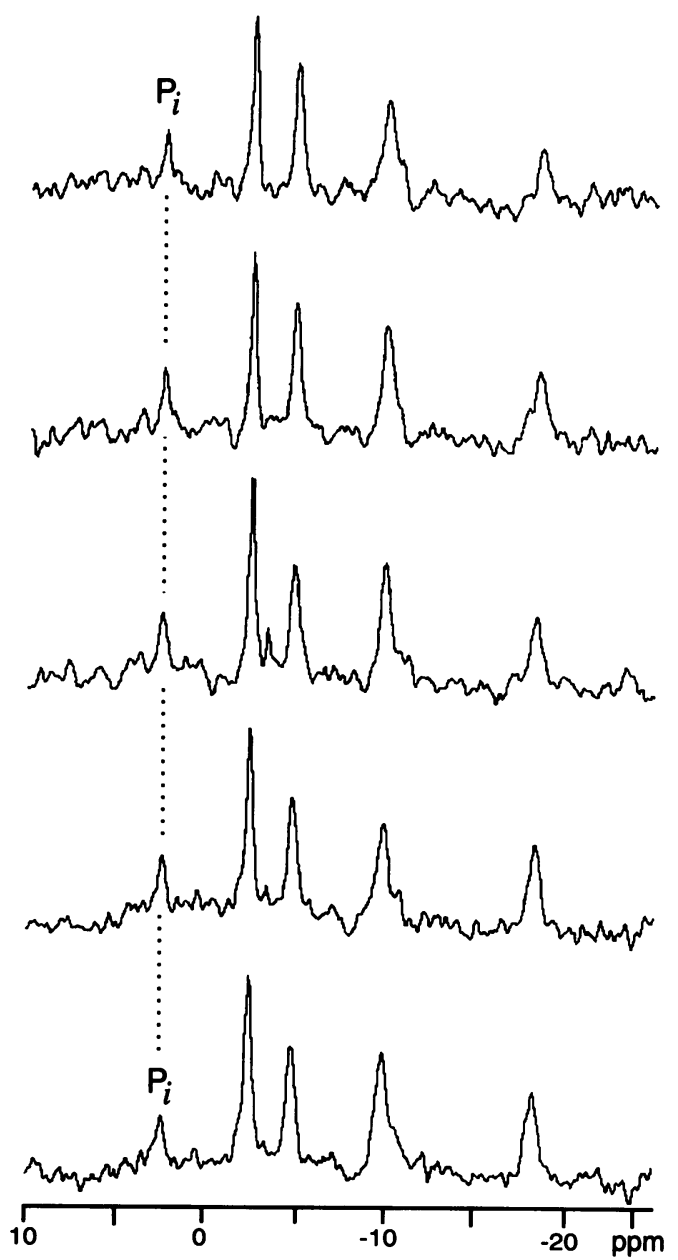

Figure 4. Transmural response of phosphorylated metabolites detected by ${ }^{31} \mathrm{P}-\mathrm{NMR}$ during sinus rhythm and during pacing at 240 beats per min in an LVH heart.

Table VII. Myocardial $P_{\mathrm{i}} /$ ATP Ratios in Three Transmural Layers of the Left Ventricle During Control Conditions and in Response to Pacing in 8 Normal Animals and 10 Animals with LVH

\begin{tabular}{lccc}
\hline & Subepicardium & Midwall & Subendocardium \\
\hline Control & & & \\
$\quad$ Normal & 0 & 0 & 0 \\
LVH & 0 & 0 & 0 \\
Pacing 200 beats per min & & & \\
$\quad$ Normal & 0 & 0 & 0 \\
LVH & $0.11 \pm 0.06$ & $0.14 \pm 0.06$ & $0.23 \pm 0.09^{* \ddagger}$ \\
Pacing 240 beats per min & & & 0 \\
$\quad$ Normal & 0 & 0 & $0.47 \pm 0.06^{* \ddagger \S}$ \\
LVH & $0.19 \pm 0.07$ & $0.38 \pm 0.06^{* \ddagger}$ & 0.47
\end{tabular}

Values are mean \pm SEM. ${ }^{*} P<0.05$ in comparison with the respective Control measurement. $\quad{ }^{\ddagger} P<0.05$ in comparison with Normal. ${ }^{\S} P<0.05$ in comparison with the respective subepicardial layer. tics, including changes in cellular enzyme content and isoforms.

Consistent with this view, previous investigators (32-35) have reported many changes in the activities and isozyme distributions of enzymes associated with metabolism in hypertrophied hearts. Several groups have found increased glycolytic

Table VIII. Subepicardial Biopsy ATP Values from Eight Normal Animals and Four Animals with LVH

\begin{tabular}{|c|c|c|}
\hline & \multicolumn{2}{|c|}{ ATP } \\
\hline & Mean & Range \\
\hline & \multicolumn{2}{|c|}{$\mu \mathrm{mol} / \mathrm{g} d r y w t$} \\
\hline Normal & $23.9 \pm 0.84$ & $19.9-27.4$ \\
\hline LVH & $14.7 \pm 0.42^{*}$ & $13.6-15.6$ \\
\hline
\end{tabular}

Values are mean \pm SEM. ${ }^{*} P<0.05$ in comparison with Normal. 
Table IX. Total Creatine Levels in Three Transmural Layers of the left Ventricle from Eight Normal Animals and Five Animals with $\mathrm{LVH}$

\begin{tabular}{lcccc}
\hline & \multicolumn{4}{c}{ Creatine } \\
\cline { 2 - 4 } & EPI & MID & ENDO & Mean \\
\hline \multirow{5}{c}{$\mu m o l / g d r y w t$} \\
Normal & $113 \pm 3.6$ & $116 \pm 2.9$ & $114 \pm 3.1$ & $115.8 \pm 3.0$ \\
LVH & $86.1 \pm 4.6^{*}$ & $98.6 \pm 6.5^{*}$ & $90.8 \pm 7.7^{*}$ & $89.5 \pm 5.0^{*}$
\end{tabular}

Values are mean \pm SEM. ENDO, subendocardium, EPI, subepicardium, MID, midwall, LVH, left ventricular hypertrophy. ${ }^{*} P<0.05$ compared with Normal.

enzyme activity in hypertrophied myocardium. Ingwall et al. $(36,37)$ found an increased percentage of the fetal-type isoenzyme of CK, but decreased mitochondrial CK activity in moderately hypertrophied myocardium. Saturation transfer ${ }^{31} \mathrm{P}$ NMR studies in the setting of myocardial hypertrophy have suggested that CK forward flux is reduced (as compared with normal) during inotropic stimulation (38). Alterations in calcium $\left(\mathrm{Ca}^{2+}\right)$ dynamics, and the $\mathrm{Ca}^{2+}$ ATPase activities of myosin and the sarcoplasmic reticulum have also been described in hypertrophied myocardium, as have abnormalities of the mitochondrial/myofibrillar ratio and capillary to mitochondrial diffusion distances $(30,39-41)$. Lastly, there is evidence of a switch in substrate preference away from fatty acid utilization and toward glucose in hypertrophied myocardium (33, 4244). Many of these abnormalities, alone or in combination, could cause alterations in the kinetics of ATP synthesis such that any given rate of synthesis would be associated with higher levels of ADP. For example, a shift in substrate utilization from fatty acid to glucose in the perfused rat heart is associated with higher levels of ADP at any given level of myocardial oxygen consumption over a considerable operational range (17, 26, 29).

Osbakken et al. (38), using a canine renovascular hypertensive model, found that, during inotropic stimulation, CK forward flux was significantly decreased in moderately hypertrophied hearts as compared with normal hearts. These authors inferred that ADP levels were lower in the hypertrophied myocardium during inotropic stimulation because the CK flux rate was lower in this group. CK flux rates are driven by the concentration of the most limiting reactant, ADP. Without knowing absolute ATP and creatine levels in both groups studied by Osbakken et al. (38), ADP levels cannot be compared between the two groups and it cannot be said whether the low CK flux in the LVH group reflects lower ADP levels. If ADP and other

Table X. Calculated Myocardial ADP Values from Eight Normal Animals and Four Animals with LVH

\begin{tabular}{lc}
\hline & ADP \\
\hline & nmol/g dry $w t$ \\
Normal & $170 \pm 14$ \\
LVH & $312 \pm 23^{*}$ \\
\hline
\end{tabular}

Values are mean \pm SEM. ${ }^{*} P<0.05$ in comparison with Normal.

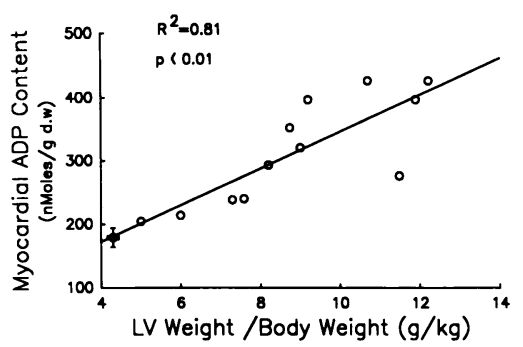

Figure 5. Relative severity of LVH expressed as the ratio of $\mathrm{LV}$ weight / body weight plotted against calculated myocardial ADP content. (Filled circle with brackets) From 8 normal hearts; ( open circles) from $12 \mathrm{LVH}$ hearts.

reactant levels were comparable in the two groups studied by Osbakken et al. (38), our inference would be that the kinetic properties of $\mathrm{CK}$ had changed or that there was less $\mathrm{CK}$ present in the LVH group. It should be noted that within each group CP fell during inotropic stimulation, suggesting that the intervention was associated with an elevation of ADP in both groups. Such an increase of ADP should have increased CK flux. Of interest, others (45) have reported that CK flux does not increase with increasing energy expenditure in normal canine myocardium, an observation at variance with that of Osbakken et al. (38). It should be noted that the animals in the present study had considerably more severe hypertrophy than those studied by Osbakken et al. (38) and may have had greater bioenergetic alterations, leading to higher ADP levels in the basal state. Lastly, neither our data nor those of Osbakken et al. (38) can be used to assess the functional significance of the CK shuttle hypothesis in the hypertrophied heart.

The influence of the severity of LVH on the CP/ATP ratio was assessed by plotting the CP / ATP ratio against LV weight / body weight ratio; a clear negative relationship was found (Fig. 6). Although animals with resting LVEDP values $>15 \mathrm{mmHg}$ tended to have the lowest $\mathrm{CP} / \mathrm{ATP}$ ratios, multiple-regression analysis showed that the addition of LVEDP did not significantly improve the relationship. This was because LVEDP was correlated with the degree of hypertrophy. A positive relationship also existed between calculated ADP levels and LV mass (Fig. 5), again suggesting that the degree to which metabolite levels are altered is a function of the severity of the hypertrophic process. In a previous study in which the bioenergetic consequences of mild hypertrophy ( $30 \%$ increase in LV mass) were examined, CP/ATP ratios were normal during basal conditions (21). These data also support the concept that the severity of the hypertrophy determines the degree of bioenergetic abnormality. Of interest, reduced CP/ATP levels have also been reported in human subjects with severe LVH and congestive heart failure and in a nonhuman primate LVH model (22,

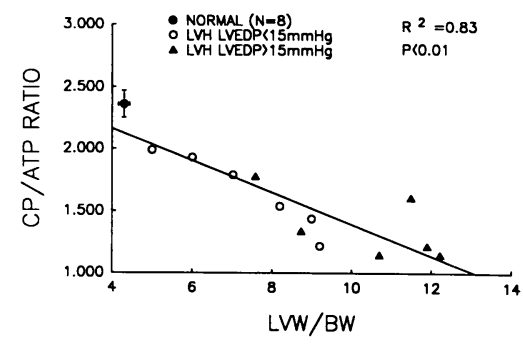

Figure 6. Relative severity of LVH expressed as the ratio of $\mathrm{LV}$ weight / body weight plotted against CP/ATP ratios. (Filled circle with brackets) From eight normal hearts; (open circles) from LVH hearts, and (filled triangles) from hearts with LVH and filling pressure $>15 \mathrm{mmHg}$. 
23). In rat models of $\mathrm{LVH}$, the greatest abnormalities of intracellular enzyme composition and bioenergetics were also associated with the more severe later stages of LVH (36).

Myocardial perfusion during tachycardia. During pacinginduced tachycardia, myocardial blood flow increased proportionately across the $\mathrm{LV}$ wall in the normal hearts whereas in the hypertrophied hearts the increase of blood flow was only seen in the outer layers. This observation is consistent with prior observations in both awake and open-chest canine models ( 6 , $7,9)$. In the hypertrophied heart, impairment of the increase in subendocardial blood flow during tachycardia is a consequence of abnormally increased extravascular forces resulting from increased LV filling pressure and decreased duration of diastole. As the subendocardium is perfused primarily during diastole, the exaggerated increase of extravascular forces in the hypertrophied hearts during pacing causes increased impedence to subendocardial blood flow. As seen in Table XI, pacing-induced tachycardia resulted in a decreased duration of diastole in both groups, but the decrease was greater in the hypertrophied group $(P<0.01)$. Moreover, the prolonged relaxation phase reported for hypertrophied hearts (40) may further contribute to the increased diastolic extravascular forces that impede blood flow in the subendocardium.

Transmural HEP distribution during tachycardia. Consistent with the observation that blood flow to the subendocardium did not increase appropriately in response to pacing in the hypertrophied group, subendocardial CP/ATP ratios fell and $\mathrm{P}_{\mathrm{i}} / \mathrm{CP}$ ratios rose in the inner myocardial layers of the hypertrophied group but not in the control group. Taken together with the observations of Path et al. (11) that graded degrees of coronary artery stenosis caused progressive reductions of the subendocardial CP/ATP ratios that were strongly correlated with the degree of hypoperfusion, the current data indicate that rapid pacing induces ischemia in the subendocardium of the hypertrophied but not the normal canine heart. The present observations, together with the previous report that exercise induces contractile dysfunction and postexercise stunning in the subendocardium of the hypertrophied canine heart (9), support the view that the subendocardium of the hypertrophied heart has increased vulnerability to ischemic injury.

Table XI. Cardiac Cycle Length and the Durations of Systole and Diastole in 8 Normal Animals and 10 Animals with LVH

\begin{tabular}{lccc}
\hline & Cardiac cycle & Systole & Diastole \\
\hline & & $m s$ & \\
Control & & & \\
Normal & $476 \pm 31$ & $244 \pm 14$ & $233 \pm 17$ \\
LVH & $470 \pm 45$ & $235 \pm 14$ & $235 \pm 32$ \\
Paced 200 & & & \\
Normal & $304 \pm 3^{\ddagger}$ & $189 \pm 4^{\dagger}$ & $114 \pm 5^{\dagger}$ \\
LVH & $302 \pm 7^{\dagger}$ & $213 \pm 9$ & $88 \pm 9^{* \dagger}$ \\
Paced 240 & & & \\
Normal & $256 \pm 2^{\dagger}$ & $165 \pm 3 \dagger$ & $92 \pm 4^{\dagger}$ \\
LVH & $248 \pm 2^{\dagger}$ & $183 \pm 3^{\dagger}$ & $66 \pm 4^{* \dagger}$ \\
& & &
\end{tabular}

Values are mean \pm SEM. ${ }^{*} P<0.05$ in comparison with Normal.

${ }^{\ddagger} P<0.05$ in comparison with respective control measurement.
Summary. During basal conditions the severely pressureoverloaded hypertrophied left ventricle demonstrates myocardial bioenergetic abnormalities that cannot be accounted for by perfusion inadequacies but that appear to be proportional to the degree of hypertrophy. The mechanisms underlying these abnormalities remain speculative, although a number of biochemical alterations have been demonstrated in hypertrophied myocardium that could contribute to the observed metabolic abnormalities. In contrast, the pacing-induced bioenergetic abnormalities in the subendocardium of the severely hypertrophied heart are closely related to the pacing-induced perfusion abnormalities and likely reflect subendocardial ischemia.

\section{Acknowledgments}

This work was supported by U.S. Public Health Service grants HL21872 and HL-32427 and Department of Veterans Affairs Medical Research Funds. Dr. Zhang was supported by a research fellowship from the Minnesota Affiliate of the American Heart Association.

\section{References}

1. Hood, W. P., C. E. Rackley, and E. Rolette. 1968. Wall stress in the normal and hypertrophied left ventricle. Am. J. Cardiol. 22:550-558.

2. Gunther, S., and W. Grossman. 1979. Determinants of ventricular function in pressure overload hypertrophy in man. Circulation. 59:679-688.

3. Levy, D., R. Garrison, and W. P. Castelli. 1990. Prognostic implications of echocardiographically determined left ventricular mass in the Framingham heart study. N. Engl. J. Med. 322:1561-1566.

4. Koren, M., R. B. Deverux, and J. H. Laragh. 1991. Relation of left ventricular mass and geometry to morbidity in uncomplicated essential hypertension. Ann. Intern. Med. 114:3345-3352.

5. Meerson, F. Z. 1969. The myocardium in hyperfusion, hypertrophy and heart failure. Circ. Res. 25:II1-II8.

6. Bache, R. J., T. R. Vrobel, and W. S. Ring. 1981. Regional myocardial blood flow during exercise in dogs with chronic left ventricular hypertrophy. Circ. Res. 49:742-750.

7. Bache, R. J., C. E. Arentzen, A. B. Simon, and T. R. Vrobel. 1984. Abnormalities in myocardial perfusion during tachycardia in dogs with left ventricular hypertrophy: metabolic evidence for myocardial ischemia. Circulation. 69:409417.

8. Goodwin, J. R. 1973. Hypertrophic disease of the myocardium. Prog. Cardiovasc. Dis. 16:199-238.

9. Hittinger, L., R. P. Shannon, and S. F. Vatner. 1990. Exercise-induced subendocardial dysfunction in dogs with left ventricular hypertrophy. Circ. Res. 66:329-343.

10. Scheafer, S., G. G. Schwartz, J. R. Gober, A. K. Wong, S. A. Camancho, B. Massie, and M. W. Weiner. 1990. Relationship between myocardial metabolites and contractile abnormalities during graded regional ischemia. Phosphorous-31 nuclear magnetic resonance studies of porcine myocardium in vivo. J. Clin. Invest. 85:706-713.

11. Path, G., P. Robitaille, H. Merkle, M. Tristani, J. Zhang, A. H. L. From, M. Garwood, R. J. Bache, and K. Ugurbil. 1990. The correlation between transmural high energy phosphate levels and myocardial blood flow in the presence of graded coronary stenosis. Circ. Res. 67:660-673.

12. Robitaille, P.-M., M. Tristiani, G. Path, H. Merkle, J. Zhang, M. Garwood, A. H. L. From, R. J. Bache, and K. Ugurbil. 1990. The correlation between transmural high energy phosphate, endocardial function, and blood-flow distribution during regional myocardial ischemia induced by coronary stenosis. In Book of Abstracts, Society of Magnetic Resonance in Medicine, Berkeley. 250 pp.

13. Hendrich, K., H. Merkle, M. Garwood, and K. Ugurbil. 1991. Phase-modulated rotating-frame spectroscopic localization using an adiabatic plane-rotation pulse and a single surface coil. J. Magn. Reson. 92:258-275.

14. Robitaille, P., H. Merkle, E. Sublett, K. Hendrich, B. Lew, G. Path, A. H. L. From, R. J. Bache, M. Garwood, and K. Ugurbil. 1989. Spectroscopic imaging and spatial localization using adiabatic pulses and applications to detect transmural metabolite distribution in the canine heart. Magn. Reson. Med. 10:14-37.

15. Hendrich, K., H. Liu, H. Merkle, J. Zhang, and K. Ugurbil. 1992. B Voxel-shifting of phase-modulated spectroscopic localization techniques. $J$. Magn.

Reson. 97:486-497.

16. Sellevold, O. F. M., P. Jynge, and K. Aartad. 1986. High performance liquid chromatography: a rapid isocratic method for determination of creatine 
compounds and adenosine nucleotides in myocardial tissue. J. Mol. Cell. Cardiol. $18: 517-527$.

17. From, A. H. L., S. D. Zimmer, S. P. Michurski, P. Mohanakrishnan, V. K. Ulstad, W. J. Thoma, and K. Ugurbil. 1990. Regulation of the oxidative phosphorylation rate in the intact cell. Biochemistry. 29:3731-3743.

18. Enzig, S., and J. J. Leonard. 1981. Changes in myocardial blood flow and variable development of hypertrophy after aortic banding in puppies. Cardiovasc. Res. 15:711-719.

19. Rembert, J. C., and L. H. Keunman. 1979. Myocardial blood flow distribution in concentric left ventricular hypertrophy. J. Clin. Invest. 62:379-388.

20. Marcus, M. L., T. M. Mueller, and C. L. Eastham. 1981. Effects of shortand long-term left ventricular hypertrophy on coronary circulation. Am. J. Physiol. 241:H358-H362.

21. Zhang, J., G. Path, M. Garwood, A. From, K. Ugurbil, and R. J. Bache. 1991. Transmural bioenergetic response to increased work in the pressure overloaded hypertrophied left ventricle. Circulation. 84:II-559.

22. Douglas, D., F. Salinas, and R. Walsh. 1989. In vivo phosphorus-31 NMR spectroscopy of abnormal myocardial energetics during stress in hypertrophied baboon hearts. Circulation. 80:II-588.

23. Conway, M. A., and G. Radda. 1991. Detection of low phosphocreatine to ATP ratio in failing hypertrophied human myocardium by ${ }^{31} \mathrm{P}$ magnetic resonance spectroscopy. Lancet. 338:973-976.

24. Fox, A., and G. Reed. 1965. High energy phosphate compounds in the myocardium during experimental congestive heart failure. Purine and pyrimidine nucleotides, creatine, and creatine phosphate in normal and in failing hearts. J. Clin. Invest. 44:202-218.

25. Scholz, P. M., G. J. Grover, J. W. Mackenzie, and H. R. Weiss. 1990 Regional oxygen supply and consumption balance in experimental left ventricular hypertrophy. Basic Res. Cardiol. 85:575-584.

26. Ugurbil, K., M. Petein, R. Maidan, S. Michurski, and A. H. L. From. 1986. Measurement of an individual rate constant in the presence of multiple exchanges: application to myocardial creatine kinase reaction. Biochemistry. 25:100-107.

27. Matthews, P. M., J. L. Bland, D. G. Gadian, and G. K. Radda. 1982. A ${ }^{31}$ P NMR saturation transfer study of the regulation of creatine kinase in the rat heart. Biochim. Biophys. Acta. 721:312-320.

28. Robitaille, P.-M., H. Merkle, B. Lew, G. Path, K. Hendrich, P. Lindstrom, A. H. L. From, M. Garwood, R. J. Bache, and K. Ugurbil. 1990. Transmural high energy phosphate distribution and response to alterations in workload in the normal canine myocardium as studied with spatially localized ${ }^{31}$ P NMR spectroscopy. Magn. Reson. Med. 16:91-116.

29. Zimmer, S. D., K. Ugurbil, S. P. Michurski, P. Mohanakrishnan, V. K. Ulstad, J. E. Foker, and A. H. L. From. 1989. Alterations in oxidative function and respiratory regulation in the post-ischemic myocardium. J. Biol. Chem. 264:12402-12411.

30. Tomanek, R. J., C. V. Gisolf, C. A. Bauer, and P. J. Palmer. 1988.
Coronary vasodilator reserve, capillarity and mitochondria in trained hypertensive rats. J. Appl. Physiol. 64:1179-1183.

31. Fitch, C. D., and R. P. Shields. 1966. Creatine metabolism in skeletal muscle. I. Creatine movement across muscle membranes. J. Biol. Chem. 241:3611-3614

32. Koehler, U., and I. Medugorac. 1985. Left ventricular enzyme activities of the energy-supplying metabolism in Goldblatt-II rats. Res. Exp. Med. 185:299307.

33. Taegtmeyer, H., and M. L. Overturf. 1988. Effects of moderate hypertension on cardiac function and metabolism in the rabbit. Hypertension (Dallas). 11:416-426.

34. Smith, S. H., M. F. Kramer, I. Reis, S. P. Bishop, and J. S. Ingwall. 1990. Regional changes in creatine kinase and myocyte size in hypertensive and nonhypertensive cardiac hypertrophy. Circ. Res. 67:1334-1344.

35. Fox, C. A., and G. E. Reed. 1969. Changes in lactate dehydrogenases composition of hearts right ventricular hypertrophy. Am. J. Physiol. 216:10261033.

36. Ingwall, J. S. 1985. The hypertrophied myocardium accumulates the MBcreatine kinase isoenzyme. Eur. Heart J. 5(Supplement F):129-139.

37. Ingwall, J. S., D. E. Atkinson, K. Clarke, and J. K. Fetters. 1990. Energetic correlates of cardiac failure: changes in the creatine kinase in the failing myocardium. Eur. Heart J. 11:108-115.

38. Osbakken, M., P. Douglas, and T. Ivanics. 1992. Creatine kinase kinetics studied by ${ }^{31} \mathrm{P}$ NMR in a canine model of chronic hypertension induced cardiac hypertrophy. J. Am. Coll. Cardiol. 19:223-228.

39. Gibbs, C. L., I. R. Wendt, G. Kotsanas, I. R. Young, and G. Wooley. 1990. Mechanical, energetic, and biochemical changes in long-term pressure overload of rabbit heart. Am. J. Physiol. 259:H849-H859.

40. Capasso, J. M., A. Malhotra, J. Scheuer, and E. H. Sonnenblick. 1986. Myocardial biochemical, contractile, and electrical performance after imposition of hypertension in young and old rats. Circ. Res. 58:445-460.

41. Bentivegna, L. A., L. W. Ablin, Y. Kihara, and J. P. Morgan. 1991 Altered calcium handling in left ventricular pressure-overload hypertrophy as detected with aequorin in the isolated, perfused ferret heart. Circ. Res. 69:15381545.

42. Yonekura, Y., A. B. Brill, P. Som, K. Yamamoto, S. C. Srivastava, J. Iwai, D. R. Elmaleh, E. Livni, H. W. Strauss, M. M. Goodman, et al. 1985. Regional myocardial substrate uptake in hypertensive rats: a quantitative autoradiographic measurement. Science (Wash. DC). 227:1494-1496.

43. Bishop, S. P.. and R. A. Altschuld. 1970. Increased glycolytic metabolism in the cardiac hypertrophy and congestive failure. Am. J. Physiol. 218:153-159.

44. Wittels, B., and J. F. Spann, Jr. 1968. Defective lipid metabolism in the failing heart. J. Clin. Invest. 47:1787-1794.

45. Katz, L. A., J. A. Swain, M. A. Portman, and R. S. Balaban. 1989. Relation between phosphate metabolites and oxygen consumption of heart in vivo. Am. J. Physiol. 265:H264-H274. 